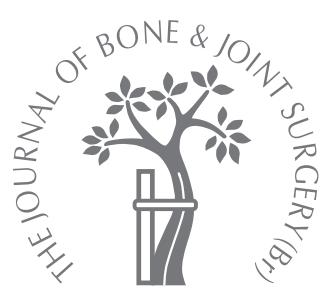

\title{
An in vitro study demonstrating that haematomas found at the site of human fractures contain progenitor cells with multilineage capacity
}

\author{
K. Oe, \\ M. Miwa, \\ Y. Sakai, \\ S. Y. Lee, \\ R. Kuroda, \\ M. Kurosaka \\ From Kobe \\ University Graduate \\ School of Medicine, \\ Kobe, Japan
}

K. Oe, MD, Orthopaedic

Surgeon

M. Miwa, MD, PhD, Assistant Professor, Orthopaedic Surgeon

Y. Sakai, MD, PhD,

Orthopaedic Surgeon

In. Y. Lee, MD, Orthopaedic

Surgeon

n. Kuroda, MD, PhD, Lecturer, Orthopaedic Surgeon

M. Kurosaka, MD, PhD,

Professor and Chairman,

Orthopaedic Surgeon

Department of Orthopaedic

Surgery

Kobe University Graduate

School of Medicine, 7-5-1

Kusunoki-cho, Chuo-ku, Kobe,

Hyogo 650-0017, Japan.

Correspondence should be sent to Dr M. Miwa; e-mail:

masahiko@med.kobe-u.ac.jp

(C)2007 British Editorial Society of Bone and Joint Surgery doi:10.1302/0301-620X.89B1. $18286 \$ 2.00$

$J$ Bone Joint Surg [Br] 2007;89-B:133-8.

Received 16 June 2006

Accepted after revision 20

September 2006

\begin{abstract}
We isolated multilineage mesenchymal progenitor cells from haematomas collected from fracture sites. After the haematoma was manually removed from the fracture site it was cut into strips and cultured. Homogenous fibroblastic adherent cells were obtained. Flow cytometry revealed that the adherent cells were consistently positive for mesenchymal stem-cell-related markers CD29, CD44, CD105 and CD166, and were negative for the haemopoietic markers CD14, CD34, CD45 and CD133 similar to bone-marrow-derived mesenchymal stem cells. In the presence of lineage-specific induction factors the adherent cells could differentiate in vitro into osteogenic, chondrogenic and adipogenic cells.

Our results indicate that haematomas found at a fracture site contain multilineage mesenchymal progenitor cells and play an important role in bone healing. Our findings imply that to enhance healing the haematoma should not be removed from the fracture site during osteosynthesis.
\end{abstract}

The haematoma occurring at a fracture site is known to play an important role in bone healing. ${ }^{1}$ Mizuno et $\mathrm{al}^{1}$ have reported that the fracture haematoma has an inherent osteogenic potential which contributes significantly to fracture healing. Grundnes and Reikeras ${ }^{2}$ reported that removal of an organised haematoma some days after fracture impaired bone healing. It is clear that within the haematoma there is a bone-forming complex that comprises cells and growth factors including platelet-derived growth factor (PDGF), acidic and basic fibroblast growth factors (aFGF and bFGF), the transforming growth factor- $\beta$ polypeptide group (TGF- $\beta$ ), and insulin-like growth factor (IGF). ${ }^{3-9}$ Previous studies have confirmed that these are central regulators of cellular proliferation, differentiation and matrix synthesis during the fracture healing process. $^{3-9}$ However, the literature shows no reports investigating the cells present in a fracture haematoma.

When a fracture occurs, haematoma forms at the site which, in the subsequent process of fracture healing, is associated with bone formation by two different mechanisms, intramembranous and endochondral. The two types serve specific purposes. Intramembranous bone formation is limited to a 'collar' of bone surrounding the fracture site, whereas endochondral ossification replaces cartilage with bone within the sheath of the intra-membranous bone at the site of the haematoma, crossing or bridging the gap between fragments of bone. The progression of endochondral bone formation in the callus to the point of bridging the fracture gap is the clinical standard for fracture healing. However, the cells from which the osteoblast and chondrocyte originate are unknown. We hypothesised that one of the origins of these cells is the haematoma. Several papers have reported that fracture haematoma contains mesenchymal cells, ${ }^{10-}$ 12 so it is assumed that such haematomas are at least a reservoir for mesenchymal progenitors, if not the actual source. However, there are no reports of detailed cellular analysis. In this in vitro study we investigated whether fracture haematoma cells (HCs) had the capacity for multilineage mesenchymal differentiation.

\section{Patients and Methods}

Fracture haematomas were obtained from five consecutive male patients with a mean age of 55.3 years (34 to 66 ) during osteosynthesis a mean of 4.2 days ( 2 to 8 ) after sustaining a fracture. The fracture sites involved were the patella in two patients, the clavicle in one, the ulna in one and the tibia in one. Patients taking anticoagulants, steroids or non-steroidal anti-inflammatory drugs in the three months prior to injury were excluded. Informed consent was obtained from all patients. The project was approved by the Ethics of Human Experiments at the Faculty of Medicine, Kobe University. 
Table I. Immunophenotypical comparison of fracture haematoma cells ( $\mathrm{HCs})$ and bone marrowderived mesenchymal stem cells (BM-MSCs)

\begin{tabular}{lcc}
\hline Cell-surface markers & HCs $^{*}$ & BM-MSCs \\
\hline CD14 & - & - \\
CD29 & ++ & ++ \\
CD34 & - & - \\
CD44 & ++ & ++ \\
CD45 & - & - \\
CD105 & + & ++ \\
CD133 & - & - \\
CD166 & + & +
\end{tabular}

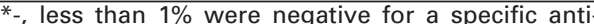
body; + , more than $40 \%$ but less than $75 \%$ were positive; ++ , more than $75 \%$ cells were positive

Isolation and culture of haematoma cells. Following exposure of the fracture site, haematoma containing organised fibrin clots was removed manually before any manipulation or irrigation, and placed in sterile polypropylene containers. The mean wet weight of haematoma obtained was $1.1 \mathrm{~g}(0.4$ to 2.0). Specimens were then washed with phosphatebuffered saline (PBS) (Wako, Osaka, Japan) to remove blood, and divided with a scalpel into small pieces with the addition of $\alpha$-Modified Minimum Essential Medium ( $\alpha$ MEM) (Sigma, St Louis, Missouri) containing 10\% heatinactivated fetal bovine serum (FBS) (Sigma), $2 \mathrm{mM} \mathrm{1-}$ glutamine (Gibco BRL, Grand Island, New York) and antibiotics (penicillin G, 100 units/ml and streptomycin $100 \mu \mathrm{g} / \mathrm{ml}$ ) on a $100 \mathrm{~mm}$ diameter culture dish. The cultures were incubated at $37^{\circ} \mathrm{C}$ with $5 \%$ humidified $\mathrm{CO}_{2}$. Five to seven days after initial incubation the culture medium was changed, and thereafter changed twice weekly. After one week of culture, the flask was washed with PBS to remove non-viable cells and debris. At a mean of 15.8 days (13 to 19 ) later, the adherent cells were harvested with $0.05 \%$ trypsin- $0.02 \%$ ethylenediaminetetraacetic acid (EDTA) (Wako) and passed into non-coated 75 $\mathrm{cm}^{2}$ culture flasks at a density of approximately $2 \times 10^{5}$ cells per flask to allow for further expansion.

Population-doubling is the method of proliferative capacity of HCs. From the calculation of population doublings, HCs could be cultured at least through the first ten passages, and there was minimal decline in proliferative capacity.

The population-doubling level was calculated for each subcultivation using the following equation:

population doublings $=\left[\log _{10}\left(\mathrm{~N}_{\mathrm{H}}\right)-\log _{10}\left(\mathrm{~N}_{1}\right)\right] / \log _{10}(2)$

where $\mathrm{N}_{1}$ is the inoculum number, $\mathrm{N}_{\mathrm{H}}$ the cell harvest number and log, the logarithm. ${ }^{13}$ The calculated population-doubling increase was added to the populationdoubling levels of the previous passages to yield the cumulative population-doubling level.

Cells that had undergone one to three passages were used in the following differentiation assays.
Immunophenotyping of haematoma cells by flow cytometry. Antibodies against cluster differentiation (CD)29, CD34, CD45, CD133 and CD166 were purchased from BD Biosciences (San Jose, California). Antibody against CD105 was purchased from Ancell (Bayport, Minnesota), and antibodies against CD14 and CD44 were purchased from Exalpha Biologicals (Watertown, Massachussets). The adherent cells were harvested after the first passage and a total of $5 \times 10^{5}$ was resuspended with PBS-3\% FBS and incubated with the phycoerythrin (PE)-conjugated antibodies for 30 minutes at $4^{\circ} \mathrm{C}$. The fluorescence intensity of the cells was analysed using a fluorescence activated cell sorting (FACS saria) flow cytometry system (BD Biosciences). In order to compare the data with those of bone marrowderived mesenchymal stem cells (BM-derived MSCs), BM samples were obtained with informed consent from five separate patients with a mean age of 45.6 years (15 to 75 ) who were undergoing hip or knee surgery, and cultured under the same conditions as the HCs (Table I). The samples were scored as ++ if more than $75 \%$ of the cells were positive, + if more than $40 \%$ but less than $75 \%$ were positive, - if less than $1 \%$ were negative for a specific antibody. Differentiation of haematoma cells

Osteogenic induction. Adherent cells were cultured for 21 days in an osteogenic medium consisting of the original medium, plus $10 \mathrm{nM}$ dexamethasone (Dex)(Sigma), 10 $\mathrm{mM} \beta$-glycerophosphate (Sigma) and $50 \mu \mathrm{g} / \mathrm{ml}$ acorbic acid (Wako). ${ }^{14-16}$ After three weeks, osteogenic differentiation was evaluated by calcium deposition, which was stained with $1 \%$ alizarin red S (Hartman Leddon, Philadelphia, Pennsylvania). Expression of osteoblast-related genes, alkaline phosphatase (ALP) and osteocalcin was also measured by reverse transcription polymerase chain reaction (RTPCR). After three weeks, ALP activities were assayed. The cell layer from each well was washed twice with PBS, sonicated with a Microson Ultrasonic Cell Diaruptor XL2000 (Misonix, Farmingdale, New York) and stored at $-20^{\circ} \mathrm{C}$ until assayed for ALP activity. ALP activity was measured by optically monitoring the change in $p$-nitrophenyl phosphate solution density at $410 \mathrm{~nm}$ caused by the ALPmediated release A $p$-nitrophenol. The optical densities obtained were compared with a p-nitrophenol standard solution (Sigma). Protein concentration in the sonicate was measured using a DC Protein Assay kit (BIO-Rad, Heracules, California) with the results expressed as $p$-nitrophenol produced in $\mathrm{nmol} / \mathrm{mg}$ of protein.

Chondrogenic induction. For chondrogenic differentiation, a pellet culture was performed for three-dimensional culture. ${ }^{16}$ About $2.5 \times 10^{5}$ cells in the $15 \mathrm{ml}$ polypropylene tube were centrifuged at $2000 \mathrm{rpm}$ for four minutes to form a pellet. The cells were resuspended in chondrogenic medium consisting of high-glucose Dulbecco's Modified Eagle's Medium (DMEM) (Invitrogen, Carlsbad, California) with $10^{-7} \mathrm{M}$ Dex, $50 \mu \mathrm{g} / \mathrm{ml}$ l-ascorbic acid-2-phosphate (Sigma), $0.4 \mathrm{mM}$ proline (Sigma), 1\% ITS ${ }^{+} 1$ 
Table II. Primers used for amplication

\begin{tabular}{|c|c|}
\hline Primer* & Sequences (sense/antisense) \\
\hline \multirow[t]{2}{*}{ ALP } & 5'-CCCAAAGGCTTCTTCTTG-3' \\
\hline & 5'-CTGGTAGTTGTTGTGAGC-3' \\
\hline \multirow[t]{2}{*}{ OC } & 5'-TCACACTCCTCGCCCTATTGG-3' \\
\hline & $5^{\prime}$-GGGCAAGGGGAAGAGGAAAGA-3' \\
\hline \multirow[t]{2}{*}{ Col II } & 5'-TCTGCAACATGCAGACTGGC-3' \\
\hline & 5'-GAAGCAGACAGGCCCTATGT-3' \\
\hline \multirow[t]{2}{*}{ Sox9 } & 5'-AACATGACCTATCCAAGCGC-3' \\
\hline & 5'-ACGATTCTCCATCATCCTCC- $3^{\prime}$ \\
\hline \multirow[t]{2}{*}{ LPL } & 5'-GAGATTTCTCTGTATGGCACC-3' \\
\hline & 5'-CTGCAAATGAGACACTTTCTC-3' \\
\hline \multirow[t]{2}{*}{ PPAR- $\gamma 2$} & 5'-TGGGTGAAACTCTGGGAGATTC-3' \\
\hline & 5'-CATGAGGCTTATTGTAGAGCTG-3' \\
\hline \multirow[t]{2}{*}{ GADPH } & 5'-CCACCCATGGCAAATTCCATGGCA-3' \\
\hline & 5'-TCTAGACGGCAGGTCAGGTCCACC-3' \\
\hline
\end{tabular}

(Sigma), $10 \mathrm{ng} / \mathrm{ml}$ recombinant human TGF- $\beta 3$ (R\&D Systems, Minneapolis, Minnesota), and $500 \mathrm{ng} / \mathrm{ml}$ recombinant human bone morphogenic protein-6 (BMP-6) (Sigma). ${ }^{16}$ After 21 days, chondrogenic differentiation was assessed by staining with toluidine blue (Muto Pure Chemicals, Tokyo, Japan). Expression of chondrocyte-specific genes, type II collagen (Col II) and sry-type high-mobility group box 9 (Sox9) was also measured by RT-PCR.

Adipogenic induction. To induce adipogenic differentiation, cells were cultured for three weeks in an adipogenic medium consisting of low-growth DMEM (Sigma) with $1 \mu \mathrm{M}$ Dex, $0.5 \mathrm{mM}$ 3-isobutyl-1-methylxanthine (Sigma), $10 \mu \mathrm{g} / \mathrm{ml}$ insulin (Sigma), $0.2 \mathrm{mN}$ indometacin (Sigma), and $10 \%$ FBS. ${ }^{16}$ After three weeks, adipogenic differentiation was evaluated by the cellular accumulation of neutral

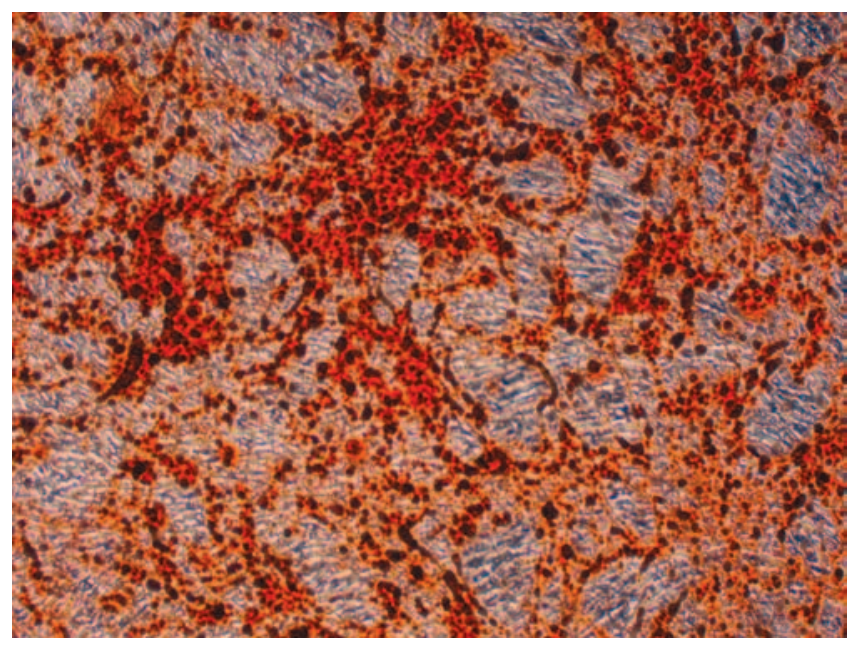

Fig. 1a lipid vacuoles that were stained with oil-red O (Muto Pure Chemicals). Expression of adipocyte-specific genes, lipoprotein lipase (LPL) and peroxisome proliferator-activated receptor (PPAR)- $\gamma 2$ was also measured by RT-PCR.

Total RNA extraction and RT-PCR. To detect mRNA levels of specific genes related to each differentiation event, differentiated and undifferentiated cells were harvested. Total RNA was extracted using an RNeasy Mini Kit (Qiagen, Valencia, California), according to the manufacturer's instructions. From each sample, approximately $1 \mu \mathrm{g}$ of total RNA was reverse transcribed using oligo $(\mathrm{dT})$ primer, 2'-deoxynucleoside 5'-triphosphate (dNTP), $10 \times$ PCR buffer, $\mathrm{MgCl}_{2}$ RNase inhibitor, and Mulv Reverse Transcriptase (all from Applied Biosystems, Branchburg, New Jersey). The converted cDNA samples were amplified by PCR using Taq Gold DNA polymerase (Applied Biosystems). In all RT-PCR assays the housekeeping gene glyceraldehyde-3-phosphate-dehydrogenase (GAPDH) was analysed to monitor RNA loading. Primers used for amplification are listed in Table II.

Statistical analysis. Stat View-J 4.5 software (HULINKS Inc., Tokyo, Japan) was used for statistical analysis. To assess differences between treated and control cells, Student's two-tailed and unpaired $t$-test was performed. A value of $p<0.05$ was considered to be statistically significant.

\section{Results}

Morphological characteristics and immunophenotypes of adherent haematoma cells. In the primary culture, the adherent HCs gave rise to colonies that first became visible around the fifth day of culture as cells exhibiting a fibroblast-like spindle shape. HCs formed colonies of fibroblastlike cells observed in BM-derived MScs. The colony size increased rapidly, and after three to four weeks the cells merged and formed a subconfluent monolayer of fibroblas-

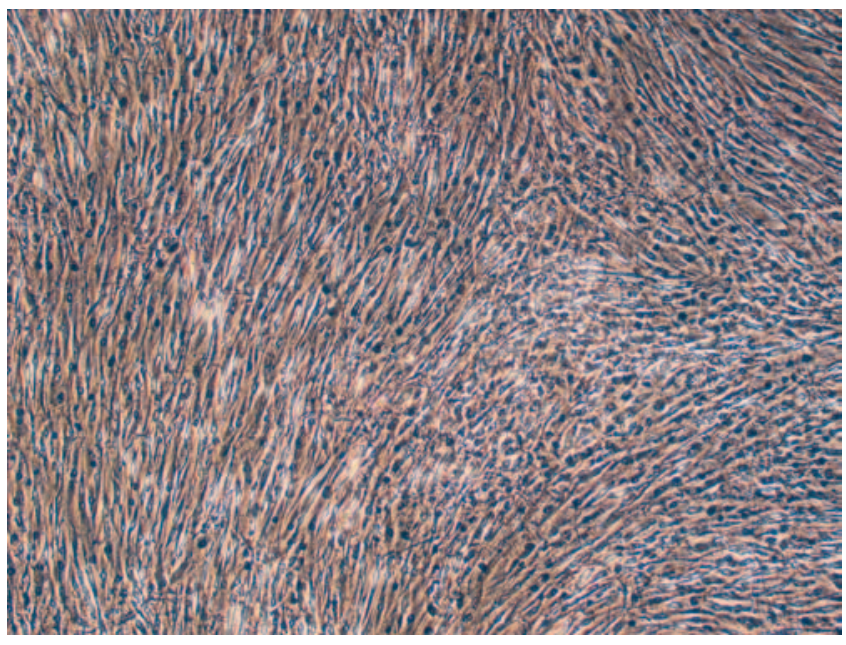

Fig. 1b

Osteogenic differentiation capacity of haematoma cells. Alizarin red S staining after 21 days incubation in a) osteogenic medium or b) undifferentiated medium (x 40). 


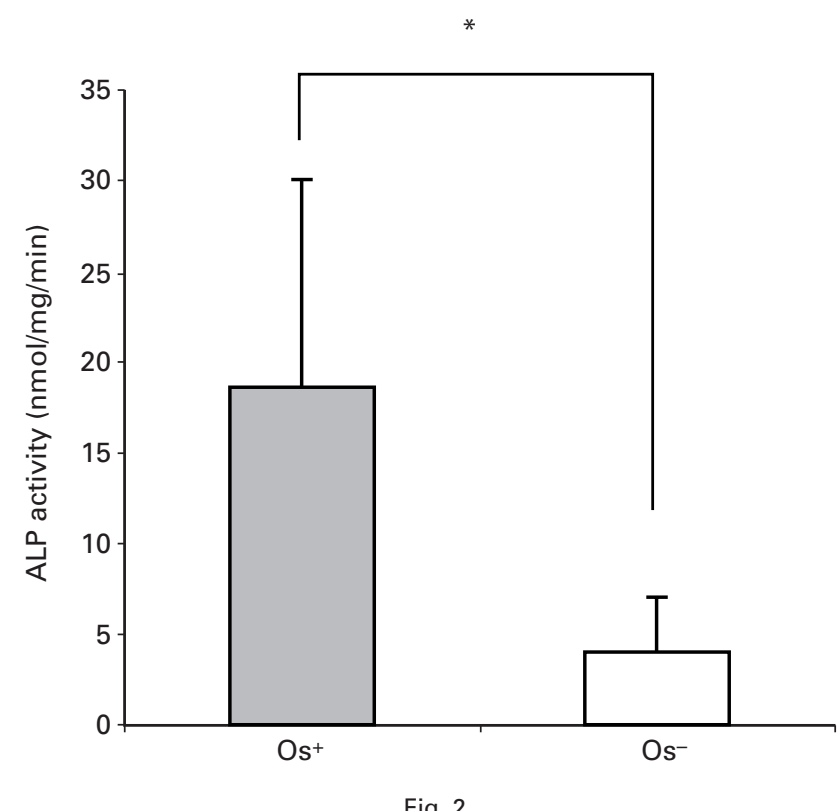

Fig. 2

Bar chart showing significantly higher alkaline phosphatase (ALP) activity in the treated $(\mathrm{Os}+)$ than in the undifferentiated (Os-) medium after 21 days in culture $\left({ }^{*} p=0.017\right.$ compared with the value of the control group; $n=5$ )

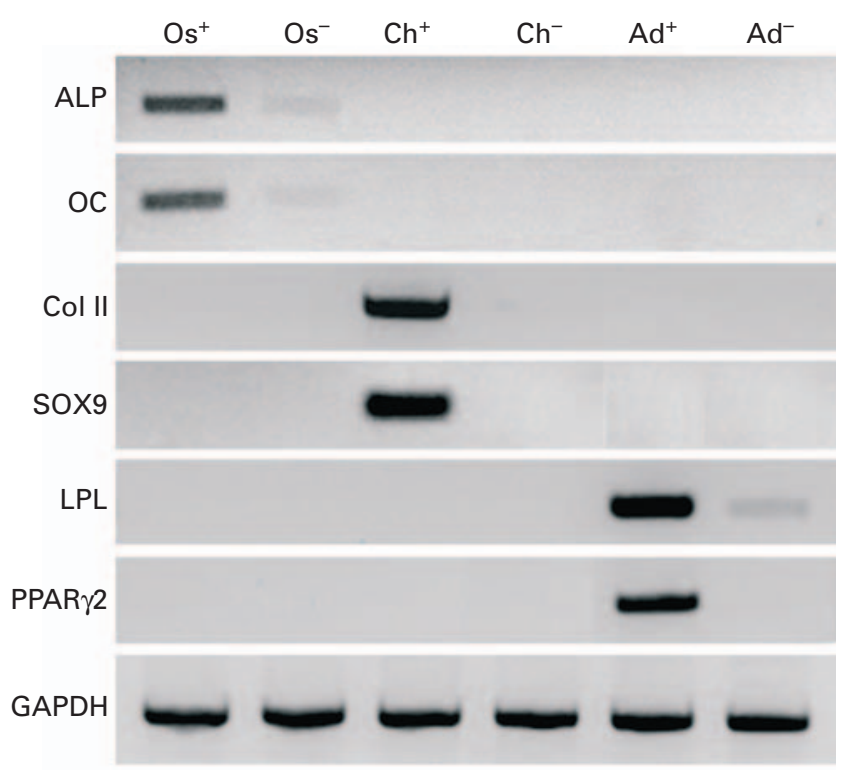

Fig. 3

RT-PCR analysis of gene expression of alkaline phosphatase (ALP), osteocalcin (OC), type II collagen (Col II), sry-type high-mobility group box 9 (SOX9), lipoprotein lipase (LPL); peroxisome proliferator-activated receptor (PPAR) 2 in the cells in differentiated medium $(\mathrm{Os}+, \mathrm{Ch}+, \mathrm{Ad}+)$ or in undifferentiated medium (Os-, Ad-) on day 21. Ch- = RT-PCR analysis of gene expression of Col II and SOX9 in the untreated cells.

toid cells. The cells were long-lived in culture and had a significant capacity for expansion. From the calculation of populations doubling, HCs could be cultured through at

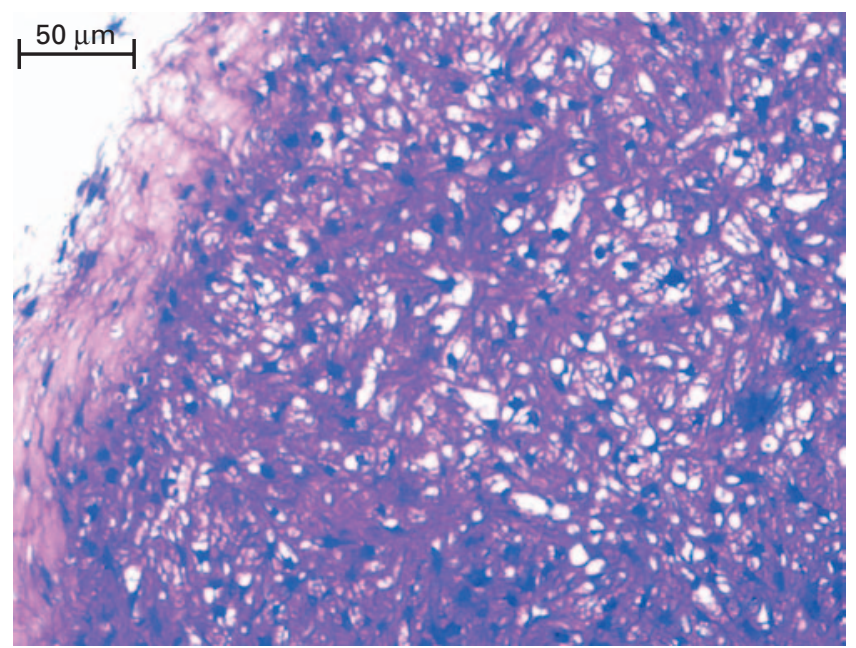

Fig. 4

Chondrogenic differentiation capacity of haematoma cells. Histological section stained with toluidine blue after 21 days incubation in chondrogenic medium (x 200).

least ten passages with a minimal decline in their proliferative capacity.

The cell-surface antigen profile of adherent HCs was analysed and compared with that of BM-derived MScs (Table I). Both HCs and BM-derived MSCs were positive for MSC-related markers CD29, CD44, CD105 and CD166, but negative for haematopoietic markers CD14, CD34, CD45 and CD133.

Adherent haematoma cells exhibited in vitro osteogenic, chondrogenic and adipogenic potential. Adherent HCs were cultured under conditions favourable for osteogenic, chondrogenic or adipogenic differentiation, respectively. After a three-week incubation under osteogenic conditions, induced cells formed a mineralised matrix as evidenced by alizarin red $\mathrm{S}$ staining (Hartman-Leddon Company, Philadelphia, Pennsylvania) in the osteogenic medium on the 21st day (Fig. 1a) contrasting with an absence of mineralised matrix under undifferentiated conditions after the same duration (Fig. 1b).

The level of ALP activity under osteogenic conditions was significantly higher $(\mathrm{p}=0.017)$ than under control conditions on day 21 (Fig. 2). This osteogenic potential was further confirmed by RT-PCR analysis, showing the expressions of ALP and osteocalcin under osteogenic conditions after a three-week culture period (Fig. 3). The expression of ALP and osteocalcin under osteogenic conditions was higher than under undifferentiated conditions in the control group (LPL $=\mathrm{ad}+: 578.23$, ad-: 100 . $p=0.040 ;$ PPAR- $\gamma 2=$ ad $+: 170.25$, ad-: $100 . p=0.043$ ).

After a three-week incubation under chondrogenic conditions, cell pellets had a spherical and glistening transparent appearance. The development of a cartilage matrix from cell pellets was shown by staining the pro- 


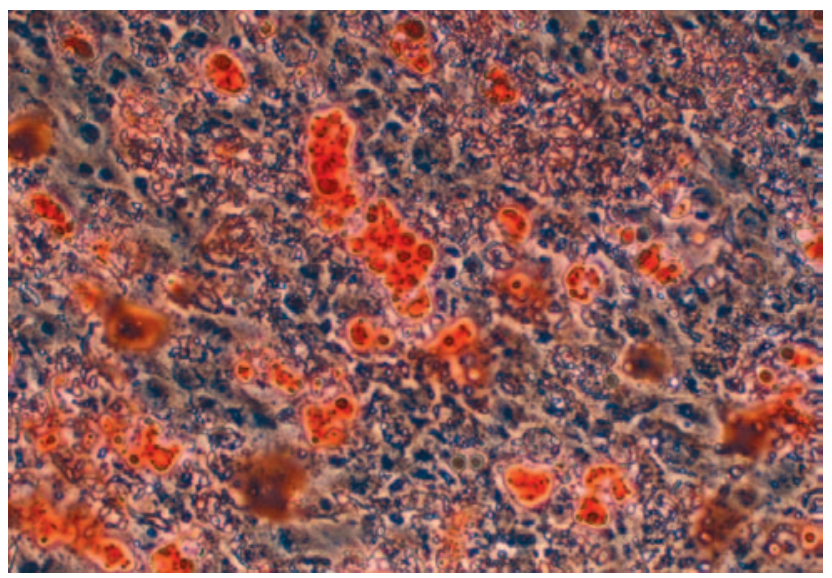

Fig. $5 a$

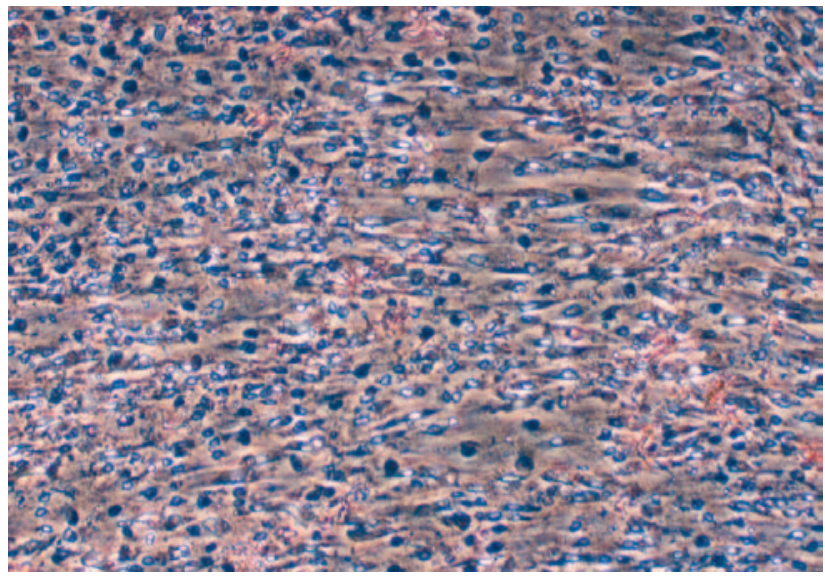

Fig. 5b

Adipogenic differentiation capacity of haematoma cells. Oil-red $\mathrm{O}$ staining after 21 days incubation in a) adipogenic medium or b) undifferentiated medium (x 80).

teoglycans with toluidine blue (Fig. 4). Expression of mRNA of Col II and Sox9 was enhanced by RT-PCR after a 21-day induction (Fig. 3).

After a three-week incubation period under adipogenic conditions, adherent HCs showed the formation of neutral lipid vacuoles, visualised by staining with oil red $\mathrm{O}$ (Fig. 5a). In contrast, in undifferentiated conditions no oil-red O-positive lipid vacuole was observed (Fig. $5 b)$. The RT-PCR analysis showed the expression of LPL and PPAR- $\gamma 2$ under adipogenic conditions after a threeweek culture period (Fig. 3). The expression of LPL and PPAR- $\gamma 2$ under adipogenic conditions was higher than that under the undifferentiated conditions in the control group.

\section{Discussion}

For the first time it has been demonstrated that cells derived from the haematoma present at a fracture site have the potential for multilineage mesenchymal differentiation in vitro. This suggests that HCs as well as growth factors play a significant and dynamic role in fracture healing.

The primary culture of adherent HCs showed the formation of colonies of fibroblast-like cells. Cell-surface markers analysed using FACS revealed that the adherent HCs expressed classical MSC marker proteins, namely CD29, CD44, CD105, and CD166, but lacked the haematopoietic markers CD14, CD34, CD45 and CD133. The capacity of HCs to differentiate into osteoblast-lineage cells that produce mineralised matrices, chondrocyte-lineage cells that produce proteoglycans, and adipocyte-lineage cells that accumulate lipid vacuoles in the presence of established lineage-specific differentiation factors in vitro was consistent with that reported for BM-derived MSCs, ${ }^{16,17}$ and was confirmed by RT-PCR analysis and histochemical evaluation. Taken together, these findings indicate that fracture haematomas contain multilineage mesenchymal progenitor cells that exhibit characteristics similar to those of BMderived MSCs.

The process of fracture healing can be divided into five distinct stages, including an initial stage in which a haematoma is formed at the fracture site associated with an inflammatory response, a subsequent stage in which angiogenesis develops and cartilage begins to form, and then three successive stages of cartilage calcification, cartilage removal and bone formation, and ultimately a more extended stage of bone remodelling. The intramembranous bone is formed by committed osteoprogenitor cells that reside in the periosteum. ${ }^{3,5}$ The presence of growth factors, specifically the TGF- $\beta$, IGF, PDGF, aFGF, and bFGF, within the haematoma is a prerequisite for the regulation of the processes that occur during fracture healing. Some reports have described that mesenchymal stem cells differentiate into osteoblasts and/or chondrocytes under the influence of several growth factors. ${ }^{16,18}$ Based on our results, one possible mechanism for fracture healing is that these growth factors may act on the HCs at different stages of healing, and the HCs then differentiate into osteoblasts and/or chondrocytes at different stages in an autocrine and/or paracrine manner. ${ }^{3-9}$

The most likely origin of HCs is the bone marrow. Several reports have described that bone marrow stromal cells (BMSCs) are essential for bone formation after fracture. ${ }^{18-}$ ${ }^{21}$ In our study, FACS analysis revealed that the phenotype of HCs was similar to that of BM-derived MSCs. Mizuno et $\mathrm{al}^{1}$ proved that fracture haematoma possesses osteogenic potential, as new bone formation was seen when the haematoma was transplanted to an intramuscular site; however, in the absence of a fracture the BM did not display this osteogenic potential. In other words, the influence of a number of factors is necessary for the differentiation of BMSCs to osteogenic cells. We postulate that exposure to 
the environment of a fracture may differentiate HCs into osteogenic and chondrogenic lineage cells. Alternatively, the origin of the osteogenic and chondrogenic lines might be the periosteum and injured muscle, as periosteumderived cells ${ }^{22-24}$ and muscle-derived cells $\mathrm{s}^{25,26}$ have been shown to differentiate into these cell lines both in vivo and in vitro. HCs may also be derived from circulating mesenchymal stem cells that enter the fracture site from the circulation via the damaged vasculature. ${ }^{27,28}$ These hypotheses will be investigated in further studies.

In fracture healing a more satisfactory result is generally achieved if stabilisation is obtained with minimal disturbance of the fracture haematoma. ${ }^{29,30}$ Usually open reduction and internal fixation result in removal of the haematoma and causes some damage to the periosteum. Our findings suggest that to enhance healing of a fracture, the haematoma should not be evacuated from the fracture site during osteosynthesis. In addition, HCs could provide a useful source of cells for tissue engineering in the future treatment of nonunion and long-bone defects. Further experiments are needed to examine whether HCs have multilineage potential in vivo.

We have shown for the first time that HCs can differentiate into osteogenic, chondrogenic and adipogenic cells in vitro, and thus contain multilineage mesenchymal progenitor cells.

\section{Supplementary Material}

苑 A further opinion by Professor Eng-Hin Lee is available with the electronic version of this article on our website at www.jbjs.org.uk

The authors wish to thank Ms Xueying Mi (Olympus Co.. Kobe, Japan) for technical assistance in flow cytometry, and Ms Kyoko Tanaka, Ms Masako Sakaguchi and Ms Minako Nagata (Department of Orthopaedic Surgery, Kobe University Graduate School of Medicine) for their technical assistance.

No benefits in any form have been received or will be received from a commercial party related directly or indirectly to the subject of this article.

\section{References}

1. Mizuno K, Mineo K, Tachibana T, et al. The osteogenic potential of fracture hematoma: subperiosteal and intramuscular transplantation of the hematoma. $J$ Bone Joint Surg [Br] 1990;72-B:822-9.

2. Grundnes $\mathbf{0}$, Reikeras $\mathbf{0}$. The importance of the hematoma for fracture healing in rats. Acta Orthop Scand 1993;64:340-2.

3. Bolander ME. Regulation of fracture repair by growth factors. Proc Soc Exp Biol Med 1992;200:165-70

4. Simmons DJ. Fracture healing perspectives. Clin Orthop 1985;200:100-13.

5. Einhorn TA. The cell and molecular biology of fracture healing. Clin Orthop 1998;355(Suppl):7-21.

6. Gronthos S, Simmons PJ. The growth factor requirements of STR0-1-positive human bone marrow stromal precursors under serum-deprived conditions in vitro. Blood 1995;85:929-40.
7. Barnes GL, Kostenuik PJ, Gerstenfeld LC, Einhorn TA. Growth factor regulation of fracture repair. J Bone Miner Res 1999;14:1805-15.

8. Bianchi G, Banfi A, Mastrogiacomo M, et al. Ex vivo enrichment of mesenchymal cell progenitors by fibroblast growth factor 2. Exp Cell Res 2003;287:98-105.

9. Dimitriou R, Tsiridis E, Giannoudis PV. Current concepts of molecular aspects of bone healing. Injury 2005;36:1392-404.

10. Wittbjer J, Palmer B, Rohlin M, Thorngren KG. Osteogenic activity in composite grafts of demineralized compact bone and marrow. Clin Orthop 1983;173:229-38.

11. Hulth A, Johnell $\mathbf{0}$, Henricson A. The implantation of demineralized fracture matrix yields more new bone formation than does intact matrix. Clin Orthop 1988;234:235-9.

12. Tuli SM, Singh AD. The osteoinductive property of decalcified bone matrix: an experimental study. J Bone Joint Surg [Br] 1978;60-B:116-23.

13. Cristofalo VJ, Allen RG, Pignolo RJ, Martin BG, Beck JC. Relationship between donor age and the replicative lifespan of human cells in culture: a reevaluation. Proc Natl Acad Sci USA 1998;95:10614-19.

14. Niikura T, Miwa M, Sakai Y, et al. Human hemarthrosis-derived progenitor cells can differentiate into osteoblast-like cells in vitro. Biochem Biophys Res Commun 2005;336:1234-40.

15. Lee SY, Mirwa M, Sakai Y, et al. Osteogenic potential of cells in vitro derived from haemarthrosis of the knee induced by injury to the anteror cruciate ligament. J Bone Joint Surg [Br] 2006;88-B:129-33.

16. Pittenger MF, Mackay AM, Beck SC, et al. Multilineage potential of adult human mesenchymal stem cells. Science 1999;284:143-7.

17. Indrawattana $\mathbf{N}$, Chen $\mathbf{G}$, Tadokoro $\mathbf{M}$, et al. Growth factor combination for chondrogenic induction from human mesenchymal stem cell. Biochem Biophys Res Commun 2004;320:914-19

18. Pountos I, Giannoudis PV. Biology of mesenchymal stem cells. Injury 2005;36:8-12.

19. Kernek CB, Wray JB. Cellular proliferation in the fracture callus in the rat tibia. Clin Orthop 1973;34:197-209.

20. Taguchi K, Ogawa R, Migita M, et al. The role of bone marrow-derived cells in bone fracture repair in a green fluorescent protein chimeric mouse model. Biochem Biophys Res Commun 2005;331:31-6.

21. Jung UY, Johnstone B. The role of osteochondral progenitor cells in fracture repair. Clin Orthop 1998;355:3-81.

22. Hui JH, Li L, Teo YH, Ouyang HW, Lee EH. Comparative study of the ability of mesenchymal stem cells derived from bone marrow, periosteum, and adipose tissue in treatment of partial growth arrest in rabbit. Tissue Eng 2005;11:904-12.

23. Brighton CT, Hunt RM. Early histological and ultrastructural changes in medullary fracture callus. J Bone Joint Surg [Am] 1991;73-A:832-47.

24. Brighton CT, Hunt RM. Early histologic and ultrastructural changes in microvessels of periosteal callus. J Orthop Trauma 1997;11:244-53.

25. Deasy BM, Li Y, Huard J. Tissue engineering with muscle-derived stem cells. Curr Opin Biotechnol 2004;15:419-23.

26. Sun JS, Wu SY, Lin FH. The role of muscle-derived stem cells in bone tissue engineering. Biomaterials 2005;26:3953-60.

27. Kuznetsov SA, Mankani MH, Gronthos S, et al. Circulating skeletal stem cells. J Cell Biol 2001;153:1133-40.

28. Eghbali-Fatourechi GZ, Lamsam J, Fraser D, et al. Circulating osteoblast-lineage cells in humans. N Engl J Med 2005;352:1959-66.

29. Redfern DJ, Syed SU, Davies SJ. Fractures of the distal tibia: minimally invasive plate osteosynthesis. Injury 2004;35:615-20.

30. Farouk 0, Krettek C, Miclau T, et al. Minimally invasive plate osteosynthesis: does percutaneous plating disrupt femoral blood supply less than the traditional technique? J Orthop Trauma 1999:13:401-6. 